\title{
Non-fed Aquaculture - An Alternative Livelihood Option for Fisherman
}

\author{
Rameshwar Venkatrao Bhosle*, Stephen Sampath Kumar and R. Somu Sunder Lingam \\ ${ }^{1}$ Dept. of Aquaculture, Fisheries College and Research Institute, Tuticorin-628 \\ 008, Tamil Nadu, India \\ ${ }^{2}$ Directorate of Sustainable Aquaculture, Tamil Nadu Dr. J. Jayalalithaa Fisheries \\ University, Thanjavur-614 904, Tamil Nadu, India \\ ${ }^{3}$ Krishnagiri-Barur Centre for Sustainable Aquaculture, Tamil Nadu Dr. J. Jayalalithaa \\ Fisheries University, Barur, Krishnagiri-635 201, Tamil Nadu, India
}

*Corresponding author

\section{A B S T R A C T}

\section{Keywords}

Rearing,

Transportation

platform, Source of

medicines, Climate regulation, Oxygen supply

\section{Article Info}

\section{Accepted:}

22 January 2021

Available Online:

10 February 2021
The aquaculture activity can be simply classified into fed and non-fed culture based on its feed supplementation. In non-fed culture systems, fish is completely relying on natural food present in the captive conditions to fulfill their nutritional requirement and there will not be any supplementation of pellet feed. Nowadays, most of fish farmers are focusing on mariculture and they are growing mussels, seaweed, oysters and clams, etc., different part of world. Present production of the unfed species aquaculture production is $54.4 \mathrm{mmt}$, including seaweeds, which comprises of filterfeeding finfish $(8.8 \mathrm{mmt})$, and aquatic invertebrates $(15.6 \mathrm{mmt})$ and aquatic plants $(30$ $\mathrm{mmt}$ ). The share of un-fed species to the total aquaculture production is $49.5 \%$ (FAO, 2018). Effective implementation of non-fed aquaculture activity at coastal sites would have various socio-economic benefits to the fish coastal farmers. The major challenge associated with non-fed aquaculture is the availability of seed. There are no wellestablished commercial hatcheries to supply the bivalve seeds; therefore, the farmers are completely depending on natural seeds for their stocking. In this context, it is wise to implement and promote the low-investment oriented eco-friendly sustainable non fed aquaculture technologies among the coastal areas to uplift the socially and economically backward stakeholders of this sector.

\section{Introduction}

Ocean, being a largest aquatic ecosystem in the earth, provides many benefits, other than just simply supplying foods to the human beings, such as transportation platform, source of medicines, climate regulation, oxygen supply and other recreational activities. Unlike in earlier days, the present anthropogenic era posing a severe threat to this mega biodiversified ecosystem which in turn heavily depleting the present fauna and flora of the 
sea. In very soon, the climatic changes going to modify what we eat. Since, from prehistoric times, fish is the major animal protein in human diet, especially the marine fish consumption pattern among the coastal country people. In addition to just satisfy the human nutritious demand, from long back, fish had a great commercial interest due to its heavy market demand and fast growing behaviour, which lead to the rearing of fish in captive conditions.

Aquaculture is the cheapest human food production industry which recording a fastest growth in the world. It encompasses of rearing aquatic animals in fresh as well as marine water environment. In future, rearing of fish in marine environment is going to be the major food production sector due to declined fish catches from marine capture fisheries.

Initially, aquaculture was practiced as natural stocking and harvesting, without much technological interventions. However, after 1970's, the intense effort from scientific communities introduced various technological up gradations which directly paved the way for commercial fed aquaculture system. In fed fish culture, heavily stocked fish is supplemented with completely balanced nutritious diet under captive conditions to reach its marketable size. Subsequently, the introduction of fed culture boomed the fish production through commercial aquaculture activities. In 2016, the global fish production was $171 \mathrm{mmt}$, of which aquaculture produced $80.1 \mathrm{mmt}$ (47\%) of fish (FAO, 2018). Equally, the evolution of fed aquaculture introduced various environmental as well as social issues throughout the world.

On the other side, in remote areas of the world, where these technologies were unable to reach the people, still fish culture is being practiced as traditional method - non-fed aquaculture. In addition to this, cultivation of some fish species and aquatic plants do not require any additional supply of supplementary feed during its grow-out operation.

\section{Non-fed aquaculture}

The aquaculture activity can be easily classified into fed and non-fed culture based on its feed supplementation. In non-fed culture systems, fish is completely relying on natural food present in the captive conditions to fulfil their nutritional requirement and there will not be any supplementation of pellet feed. It is a kind of extensive - traditional fish culture system. In these system aquatic plants, filter feeding mollusc and filter feeding carps were raised. The technological interventions introduced in fed farming system helped them to outpace the farming of unfed species in world aquaculture. In the modern days, since from 2000's, the production of unfed species is gradually decreasing from day by day. In contrary, the quantity of un-fed species production is still expanding, but the growth is too slower than fed species production. At present, the unfed species aquaculture production is $54.4 \mathrm{mmt}$, including seaweeds, which comprises of filter-feeding finfish (8.8 $\mathrm{mmt}$ ), and aquatic invertebrates (15.6 $\mathrm{mmt}$ ) and aquatic plants $(30 \mathrm{mmt})$. The share of unfed species to the total aquaculture production is $49.5 \%$ (FAO, 2018).

Filter feeding carps such as silver carp and big head carp are the important species in non-fed based multispecies polyculture where they maintain the water quality and improve the production of the system by grazing the natural food. The marine bivalve, an extractive species of organic matter for growth, was reared in marine water environment like seas, coastal lagoons and ponds. Seaweeds, photosynthetic macro algae, are cultured along the coastal areas to utilize the dissolved nutrients present in the coastal ecosystem. 


\section{Benefits of non-fed aquaculture}

Effective implementation of non-fed aquaculture activity at coastal sites would have various socio-economic benefits;

Provision of additional food source and nutritional security to the socially and economically backward community.

The generation of additional income and create an alternative employment opportunity.

The diversification of production sector is possible using non-fed cultivable species.

Foreign exchange earnings through export of high-value value added products.

It helps to maintain the current growth rate of the sector as well as fish production.

Through community development programmes like stocking and release of hatchery-reared organisms into coastal waters could help to balance the depleting natural resources as well as support the capture-based local fisheries.

In many parts, non-fed species are integrated with fed species culture system which helps in balancing of ecosystem through their waste and nutrients extractive behaviours.

Additionally, the establishment of value added product development industries like sea weeds extracts (algin, agar and carrageenan) and bivalve products at closer to the production sites would help to improve the employment opportunity for coastal community.

\section{Seaweed culture}

In nature, seaweeds are attached to a solid substrate. Seaweeds, inhabitant of the lowest trophic level at aquatic ecosystem, are autotrophic organisms and remove nutrients from waters during their photosynthetic energy production process. In general, seaweeds contain good quality of proteins, fatty acids, vitamins and minerals. In the total seaweed production $(31.2 \mathrm{mmt})$, almost $96.5 \%$ (30 $\mathrm{mmt}$ ) of seaweeds were produced using non-fed aquaculture systems (FAO, 2018). Seaweeds are produced either for direct human consumption or for the production of valuable extracts. Species such as Undaria pinnatifida, Porphyra spp. and Caulerpa spp., were exclusively cultured in East and South East Asia for direct human consumption. On the other hand, tropical species like Kappaphycus alvarezii and Eucheuma spp. were mainly cultivated for their valuable extracts. The other important cultivable species are Laminariajaponica, Gracilariaspp, Sargassum spp. and the major producing countries are China, Indonesia, Philippines and Korea.

The escalating demand for important phycocolloid like alginate, agar and carrageenan pushing the industry more forward. The other major driving forces behind the growth of this industry are depletion of natural stocks, declined capture fisheries, population growth and the other environmental problems caused by intensive fed-fish farming systems. On the other side, researchers have promised the possibility of bio-fuel production from seaweeds in near future. Additionally, the nutrient extractive behaviour of seaweed making the culture activity as a more sustainable way of coastal farming. In general, seaweeds are farmed in shallow near shore waters where wave action is limited using lines; nets following either fixed to the bottom or attached to floating rafts and buoys. Though, seaweeds are cultured using different methods based on production capacity it has been classified into small scale farming (topical countries - 3-5 t dry matters/ha) and large scale farming (temperate 
countries- 26 t dry matters/ha). Other important cultivation methods include;

\section{Single rope floating raft method}

It was developed by CSMCRI to culture Gracilariaedulis and Gelidiella acerosa. In this method, a rope attached with seaweed fragments is attached between two wooden poles or stakes. The rope is assisted with floats (synthetic) and sinkers (stones) which help the rope to hung in vertical position. Some places in Gulf of Kutch and Kerala were identified as potential sites for this culture.

\section{Fixed bottom long line method}

It is mainly used to cultivate the Kappaphycus spp. In this method, the seedlings were tied in the rope at the shore area. At 6-10 m distance, wooden poles are anchored into the substratum (sea floor). Tie the seedlings rope in between the poles with a distance of 0.3 to $0.5 \mathrm{~m}$ from bottom depending on the water depth at the culture site during low tide. Gulf of Mannar (South east India) was identified as potential site for this culture.

\section{IMTA based method}

It is an integrated approach. In this method, seaweeds are cultured along with fed species to extract the organic nutrients released from fed fish culture. It is also emerging as an important cultivation technique to balance the ecosystem.

\section{Molluscan culture}

Mollusc - second largest phylum of invertebrate after arthropods - are shellfish group which mainly includes clams, mussels, oysters, abalones and scallops. The present molluscan production from aquaculture is $17.14 \mathrm{mmt}$, including freshwater molluscs, which alone contributes $21.45 \%$ in world aquaculture production. Interestingly, at global level, production of marine mollusc is out spaced the production of marine fin fish $(6.58$ $\mathrm{mmt})$ and crustaceans $(4.83 \mathrm{mmt})$ produced, and contribute $58.79 \%$ to the marine aquaculture production (FAO, 2018). At global level, almost, molluscan species were farmed in 76 countries and among them China, Vietnam, Korea, Japan and Chile are the leading producers.

\section{Clam culture}

Clam, an invertebrate having two equal shells, is the major farmed molluscan bivalve species which alone contributes $38 \%$ to the total bivalve production. Clam is considered as a delicious seafood with good amount of protein (>20\%), vitamins (Vit-B ${ }_{12}$ ) and minerals. At global level, China is the leading exporter of bivalves in 2016. The rising market demand for clams due to the promotion of healthy and sustainable food items, at global level, clam production has been increasing constantly over the past 20 years.

In the clam culture, either the naturally occurring juvenile clams will be collected or the hatchery produced seeds will be placed in a special culture beds. Later, the special culture beds were placed in the open marine environment where there is a more availability natural plankton for grow-out culture. The bed size used for clam culture is $10 \times 2 \mathrm{~m}$ with a stocking density of $200 / \mathrm{m}^{2}$.

In India, the Central Marine Fisheries Research Institute (CMFRI) has developed several farming techniques for clam culture. However, clam farming on scientific lines is yet to take off in the country. Initially, clam culture was tried at coastal pens using blood clam. Clam species like blood clam (A. granosa), black clam (Villorita cyprinoides) and short neck clam (Paphiamalabarica) were identified as most suitable species for culture 
in the upper reaches of the estuaries and backwaters of Kerala and Karnataka States. Presently, off bottom (raft) and on bottom (tray or rack) cultures are used for rearing of the clams.

\section{Oyster culture}

Oyster, a sessile molluscan bivalve with two permanent hard shells, has a soft unsegmented body which increase in size as the animal grows. Oyster culture is one of the most prominent forms of marine molluscan aquaculture. Other than having protein, vitamins and minerals, oysters has good amount of omega 3 fatty acids. There are more than 100 known species of oysters, but only few species are widely cultured. Oysters are broadly classified into edible and pearl oysters.

Edible oyster has a great market demand in western countries due to their delicious taste, medicinal supplement and nutritional value. It has a long history, since it is one among the first cultured marine species by Romans during first B.C. The important cultivable species are Crassostrea angulata, Ostreaedulis, $C$. iredalei, $C$. gigas, $C$. commercialis, C. madrasensis, C. gryphoides, C. rivularis and Saccostrea cucullata. In India, the culture is dominated in Southern districts of Kerala and the states like Maharashtra, Goa and Kerala have good market demand for oyster. Mostly, it was reared (up to 6-8 cm) using raft, rack, stake and rope methods for about 6 months in open water bodies. Presently, the farming practices are commercialized throughout the world, however, the major bottleneck associated with this culture is the non-availability of seed spat - at sufficient quantity.

Pearl oyster is a special type of bivalve mollusc which secretes a nacre, a mineral substance, over a foreign material. Pearl produced either naturally when grain of sand or any other irritant enters into the pearl shell or artificially by inserting irritant materials into shell of pearl oysters. The pearl, queen of jewel, is obtained from this species considered as symbol of wealth material, therefore, throughout the history, pearl oyster has a greater demand. Presently, almost in 30 countries pearls were produced and more dominantly in China, Japan, Australia, Indonesia and Philippines (Zhu et al., 2019). China and Japan are the largest producer of freshwater and marine pearls, respectively. The culture is typically consisting of five stages including identification of culture species, implantation of nucleus, grow-out, harvesting and extraction of pearl. Among them, implantation of nucleus is the key step. The three important marine oysters are Akoya pearl oyster (Pinctada fucata/martensii), silver lip oyster $(P$. maxima) and black lip oyster $(P$. margaritifera). In freshwater, Hyriopsis cumingii and Cristaria plicata were used as major species. After implementation of graft tissue $(3 \times 3 \mathrm{~mm})$ in nucleus, the oyster is conditioned for two weeks to observe the mortality or rejection of nucleus. Afterwards, the implanted shells kept in 2-3 m deep water for grow-out. It takes 1-2 years to produce a pearl and harvesting used to be carried out during winter season. In India, pearls were produced along the coast of Gulf of Mannar, Kerala, Lakshadweep and Andaman and Nicobar Islands.

\section{Mussel culture}

Mussel, a sedentary animal with equilateral shells, is a herbivore bivalve and which is the least contributor (13\%) among the molluscan bivalve production. The production of mussel was 1.95 million tonnes (Tamburini et al., 2020). The culture has a very old history (dates back to the $30^{\text {th }}$ century) and it is mainly practised along the coastal area for nutrient recycling. The culture was boosted by 
the successful artificial seed production during 1970's. Mussels are farmed in many areas of the world and the countries like China, Chile, Spain, Netherlands and France are the leading producers of mussels. The dominant cultivated species are Mediterranean mussel and blue mussel, Other than bouchats method, practiced along the coast of France, mussels were cultured using long line rope, rafts and rack methods. In mussel culture, the attached seeds kept in open ocean for 1-3 years for grow-out culture based on the plankton diversity and environmental conditions at the culture site. In India, mussel culture (Perna viridis and Perna indica) is becoming popular in the Malabar area due to its faster growth (good climatic condition), seed availability (natural seed resource) and loan and subsidy availability.

\section{Culture methods of molluscan bivalves}

There are many methods practiced for culturing molluscan bivalve based on the prevailing environmental conditions at the culture site. However, the culture is broadly classified into off bottom and on-bottom methods. In the first method, bivalve shell is kept above the seafloor in a container made of net like basket, cage, bag, etc. In the second method, the bivalve species connected with sea floor. Additionally, these two methods are further subdivided into various categories;

\section{Off bottom culture}

This method is widely used in Netherlands, Denmark and Germany. In this method, the greatest development has shown in recent years which offer the best prospects for future expansion. There are two basic types of suspended culture, fixed and floating rafts. Suspended culture from fixed rafts is usually practiced in bays where the depth is less than $4 \mathrm{~m}$ with very little tidal range. The main principle of this culture system is transferring seeds from areas of great abundance where growth is poor to culture plots in lower density to obtain better growth of the mussels.

Marketable mussels are fished from the plots and undergo cleaning before being sold. This method requires a minimum investment.

\section{Long line culture}

Most successful form of mussel farming in open sea water. Practiced in the shallow water area having a water depth of $10-15 \mathrm{~m}$. It consists of single long line $(60 \mathrm{~m})$ made of HPD rope with a thickness of $20-24 \mathrm{~mm}$. The rope is anchored in both the ends using concrete blocks and barrels as floats to fix ropes at $3 \mathrm{~m}$ intervals. Vertical lines $(6 \mathrm{~m})$ seeded with spats were hung at a distance of $75 \mathrm{~cm}$ between two floats from the main line.

\section{Rack culture}

It is a type of off-bottom and simplest method used for green mussel cultivation. It is mainly practiced in the Philippines, India and Italy, where sea bottom is usually soft and muddy and tidal range is narrow. In between two vertical poles, ropes were suspended either vertically or kept horizontally. In this method, the seed collector is placed over or near natural spawning grounds of the shellfish.

\section{Stake method}

It is combination of rack and bottom method, mostly practiced in the Thailand and Philippines. Mussels were grown on bamboo poles (4-6 m) which later staked firmly at the bottom in rows, where water depth is about $3.0 \mathrm{~m}$. In areas, where strong water current prevails, bamboo poles are additionally supported with long horizontal bamboos. The mussels should be always submerged in water, therefore, the tip of the pole should not protrude above the water during low tide water level. 


\section{Raft culture}

This method is most commonly practised throughout the world, especially in Spain for a long time. Raft is a frame like structure suspended in the water using floats, in which series of ropes were attached. Rafts are made using locally available materials like bamboo pole and rope. The seeds settled over either the collector rope or cultches suspended from a raft. Easy handling and high growth rate are the main advantages in raft culture. Floats can be made of plastic, wood, oil drums, etc. Overall production of clams, oyster and musselsis high in raft method as compared to others culture method.

\section{Tray culture}

In this method, a tray made up of bamboo or metal $(1.5 \mathrm{~m} \times 1 \mathrm{~m} \times 15 \mathrm{~cm})$ is used to rear the bivalves. The tray is either hangs between poles of the hanging or suspended using four bamboo posts.

\section{Hanging method}

In this method, culture is starts with the preparation of the spat collectors or cultches. In nylon ropes or strings threaded with coco fibre supported by bamboo pegs or empty oyster shells at $10 \mathrm{~cm}$ intervals are used to collect the spat. Using horizontal bamboo poles, these collectors were hung at $0.5 \mathrm{~m}$ interval. In the end of the collector rope, an anchor, a piece of steel or stone, is attached to prevent the collector to float in the surface.

\section{Bouchot culture}

Mainly practised in the France. This is also called the "pole culture". The poles are made up of big branches of oak tree, 4-6 $\mathrm{m}$ in length, which are staked in rows at $0.7 \mathrm{~m}$ in interval intertidal zone during low tide. Mostly soft and muddy bottoms are selected for easy installation. The collected mussel seeds on coco-fibre ropes stretched out horizontally between poles. Young adults, $3-5 \mathrm{~mm}$ in size, are placed in long netlon tubes $(10 \mathrm{~m}$ in length) and attached around the oak poles in a spiral fashion, until marketable size.

\section{Constraints in non-feed aquaculture}

The major challenge associated with non-fed aquaculture is the availability of seed. There are no well-established commercial hatcheries to supply the bivalve seeds, therefore, the farmers are completely depending of natural seeds for their stocking.

The market demand for the species is available away from the culture site. Mostly it has a good demand in export, on the other side, there is no good policies to support this bivalve export market.

The other major problem is bio toxins and transfer of pollutants. Since most of the bivalves strain the water to extract their food. While straining, it filters more quantity of water which leads accumulation of pollutants in their muscles.

Duration of culture is the major hurdle. Most of the stakeholders are concentrating on short term return culture activity like shrimp farming. On the other side, most of the nonfed species culture, except seaweed farming, are time consuming and takes minimum 1-2 years to get the product in the hand.

The lack of post-harvest technologies for value addition is an area where we need to concentrate in the upcoming years.

The only environment and ecosystem oriented problem in non-fed aquaculture is disturbance of local fauna and flora and siltation in the culture site. In fisheries, stakeholders, fisherman, are collecting their valuable 
resources such as fish, shellfish and aquatic plants, etc., from the natural resources. Till date, gathering is the only sustenance option for the fishermen in world. Fishermen are identical with their limited assets, weak capital structure, lack of bargaining power to access the economic resources, failure to access the market and the lack of scientific knowledge throughout the world. So, here the question is, how long they can reap and rely on this renewable resource ocean in the context of anthropogenic induced climate changing era? Cage and pen cultures, a type of fed culture, would be considered as viable option, however, to our stakeholders, purchasing of feed and the sophisticated culture technologies could be the major challenges. Therefore, a simple and fisherman cum eco-friendly culture method should be promoted in the near future. In addition to this, trophic diversification, diverting the aquaculture activities from fish and shrimp to an equally valuable molluscan and algal species such as clams, oysters, mussels and seaweeds, oriented culture activities needs to carry out to combat the current climate changes. In this context, it is wise to implement and promote the lowinvestment oriented eco-friendly sustainable non fed aquaculture technologies among the coastal areas to uplift the socially and economically backward stakeholders of this sector.

\section{References}

Angell, C. L. (1986). The biology and culture of tropical oysters (Vol. 13). World Fish.

Asokan, P. K. K. S., Mohamed and G. Sasikumar, (2015). Mussel Farming Methods and the Prospects and Problems in India.

Juanich, G. (1988). Manual of running water fish culture Eucheuma spp. Projected reports Cebu, Philippines, FAO.

Lovatelli, A. (1988). Status of oyster culture in selected Asian countries.

Quayle, D. B. (1980). Tropical oysters: culture and methods. IDRC, Ottawa, ON, CA.

Suplicy, F. M. (2020). A review of the multiple benefits of mussel farming. Reviews in Aquaculture, 12(1), 204223.

Changbo Zhu, Paul C Southgate and Ting Li. 2019. Production of pearls. Goods and Services of Marine Bivalves, pp.73-93. Tamburini, E., Turolla, E., Fano, E. A., \& Castaldelli, G. (2020). Sustainability of Mussel (Mytilus galloprovincialis) farming in the Po River Delta, Northern Italy, based on a life cycle assessment approach. Sustainability, 12(9), 3814.

\section{How to cite this article:}

Rameshwar Venkatrao Bhosle, Stephen Sampath Kumar and Somu Sunder Lingam, R. 2021. Non-fed Aquaculture - An Alternative Livelihood Option for Fisherman. Int.J.Curr.Microbiol.App.Sci. 10(02): 3181-3188. doi: https://doi.org/10.20546/ijcmas.2021.1002.349 